\title{
Akt/Ezrin Tyr353/NF- $\kappa$ B pathway regulates EGF-induced EMT and metastasis in tongue squamous cell carcinoma
}

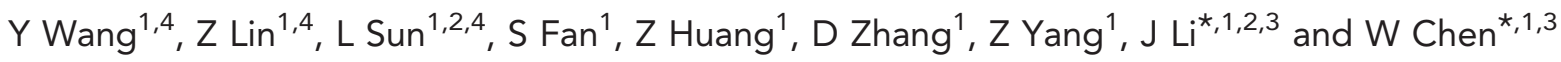 \\ ${ }^{1}$ Department of Oral and Maxillofacial Surgery, Sun Yat-sen Memorial Hospital, Sun Yat-sen University, 107 Yanjiang West Road, \\ Guangzhou 510120, People's Republic of China; ${ }^{2}$ Key Laboratory of Malignant Tumor Gene Regulation and Target Therapy of \\ Guangdong Higher Education Institutes, 107 Yanjiang West Road, Guangzhou 510120, People's Republic of China and ${ }^{3}$ Oral and \\ Cranio-maxillofacial Surgery Center, 107 Yanjiang West Road, Guangzhou 510120, People's Republic of China
}

Background: Epithelial-mesenchymal transition (EMT) is a crucial programme in cancer metastasis. Epidermal growth factor (EGF) is a key inducer of EMT, and Ezrin has an important role in this process. However, how Ezrin is activated and whether it mediates EGF-induced EMT in tongue squamous cell carcinomas (TSCCs) through activating NF- $\kappa$ B remains obscure.

Methods: We used two TSCC cell lines as a cell model to study invasion and EMT in vitro, and used nude mice xenografts model to evaluate metastasis of TSCC cells. Finally, we evaluated the level of pEzrin Tyr353, nuclear p65 and EMT markers in TSCC clinical samples.

Results: Ezrin Tyr353 was phosphorylated through Akt (but not ERK1/2, ROCK1) pathway, and lead to the activation of NF- $k \mathrm{~B}$ in EGF-treated TSCC cells. Akt and NF- $\kappa$ B inhibitors blocked EGF-induced EMT, and suppressed invasion and migration of TSCC cells. In vivo, silencing Ezrin significantly suppressed EGF-enhanced metastasis of TSCC xenografts. Finally, high levels of expression of pEzrin Tyr353, nuclear p65, vimentin and low level of expression of E-cadherin were correlated with cancer metastasis and poor patient prognosis.

Conclusion: Our data suggest that Akt/Ezrin Tyr353/NF-kB pathway regulates EGF-induced EMT and metastasis inTSCC, and Ezrin may serve as a therapeutic target to reverse EMT in tongue cancers and prevent TSCC progression.

Tongue squamous cell carcinoma (TSCC) is the most common oral cancer, which frequently leads to lymph node and distant metastasis, and metastasis is the most reliable adverse prognostic factor in TSCC patients (Sano and Myers, 2007; Jemal et al, 2009). Previous studies have demonstrated that tumour metastasis is associated with epithelial-mesenchymal transition (EMT), a biological process in which epithelial cells lose cell-cell contact, E-cadherin expression and develop mesenchymal properties, leading to enhanced motility, invasiveness, vimentin expression and resistance to apoptosis (Thiery and Sleeman, 2006; Polyak and Weinberg, 2009). Recent advances have fostered a more detailed understanding of molecular mechanisms and networks that govern EMT in tumour progression (Huber et al, 2005). The signalling pathways are always triggered by different members of the TGF $\beta$ superfamily, Wnts, Notch, EGF, HGF, FGF and HIF (Kalluri and Weinberg, 2009; Thiery et al, 2009; Chaudhury et al, 2010; Shin et al, 2010). The transcription factors include Snail, Slug, Twist, ZEB1, ZEB2/SIP1, $\beta$-catenin and NF- $\kappa$ B (Huber et al, 2004; Kudo-Saito et al, 2009; Wellner et al, 2009; Wu et al, 2009; Sánchez-Tilló et al, 2010; Vuoriluoto et al, 2010; Yip and Seow, 2012). Besides, these studies also illustrate that blocking these signal networks can inhibit EMT and cancer metastasis in vitro and

\footnotetext{
${ }^{\star}$ Correspondence: Professor W Chen; E-mail: drchen@vip.163.com or Professor J Li; E-mail: lijinsong1967@163.com

${ }^{4}$ These authors contributed equally to this work.
} 
in vivo. Therefore, EMT in tumour cells is a crucial programme in cancer metastasis, and determining the mechanisms that govern EMT is essential for the development of novel therapeutic strategies to overcome cancer metastasis.

Ezrin, the most important member of ERM (Ezrin/Radixin/ Moesin) proteins, not only involves in cytoskeleton organisation but also in transmission of signals in responses to extracellular cues (Louvet-Vallée, 2000; Arpin et al, 2011). Ezrin may function as metastasis-related oncogene (Khanna et al, 2004) by modulating multiple cellular processes, including the formation of microvilli (Chiang et al, 2008), maintenance of cell shape (Baumgartner et al, 2006), cell-cell adhesion (Srivastava et al, 2005), cell motility (Vanacker et al, 2011) and invasion (Chuan et al, 2009). Activation of Ezrin is a cellular mechanism to promote local alterations in cell morphology in response to EGF and might have a role in tumour cell metastasis (Baumgartner et al, 2006). On the other hand, the cell morphology is an important phenotype transition of EMT and EGF can initiate and sustain various aspects of the EMT pathway in normal and malignant epithelial cells (Hardy et al, 2010; Chai et al, 2012). Activation of NF- $\kappa \mathrm{B}$ by inflammatory cytokine has been implicated in the control of EMT and motility and invasiveness of tumour cells (Wu et al, 2009). More interestingly, a recent study has shown that the complex of NF- $\kappa \mathrm{B}$ and Ezrin is essential for L1 (cell-neural adhesion molecule L1CAM)-mediated metastasis of colon cancer cells (Gavert et al, 2010). Furthermore, another study suggests that NF- $\kappa \mathrm{B}$ activity is required for Ezrininduced actin polymerisation (Lim et al, 2009). Accumulating evidence has demonstrated that Ezrin may have an important role in EMT through the activation of NF- $\kappa \mathrm{B}$ pathway. However, whether Ezrin mediates EGF-induced EMT in TSCCs through activating NF- $\kappa \mathrm{B}$ remains obscure.

In the present study, we investigated the role of Ezrin in regulating EGF-induced EMT in TSCC cells at first. Then, we explored how Ezrin was activated in response to EGF, identified its phosphorylated site and detected its effect on NF- $\kappa \mathrm{B}$ activity. We defined the pathway through which EGF induced EMT in TSCC cells, and evaluated the effects of Ezrin expression on tumour growth and metastasis of TSCC xenografts. Finally, we correlated the activation of Ezrin and NF- $\kappa \mathrm{B}$ with the clinicopathological status and prognosis of TSCC patients.

\section{MATERIALS AND METHODS}

Cell culture. Human tongue cancer cell lines SCC9 and SCC25, and a human embryonic kidney cell line (HEK-293) were purchased from the American Type Culture Collection (Manassas, VA, USA). SCC9 and SCC25 were cultivated in Dulbecco's modified Eagle's medium-F12 (Gibco, Rockville, MD, USA) supplemented with $10 \%$ fetal bovine serum (Invitrogen, Carlsbad, CA, USA). Human embryonic kidney-293 cells were cultivated in Dulbecco's modified Eagle's medium (Gibco) supplemented with $10 \%$ fetal bovine serum (Invitrogen).

Transfection. Ezrin siRNAs were obtained from GenePharma (Shanghai, China) and their sequences were Ezrin siRNA1: $5^{\prime}$-GUGGGAUGCUCAAAGAUAATT- $3^{\prime}$ and Ezrin siRNA2: $5^{\prime}$-GGGCAACCAUGAGUUGUAUTT-5'. Cells were transfected with $30 \mathrm{~nm}$ siRNA using Lipofectamine 2000 (Invitrogen). Lentivirus carrying Ezrin shRNA were also obtained from GenePharma. An expression construct with wild-type Ezrin (Ez-WT) and the Y353F-Ezrin mutant (Ez-Y353F) are a kind gift from Dr Monique Arpin (Srivastava et al, 2005).

Quantitative RT-PCR. Real-time PCR was carried out using LightCycler 480 (Roche, Basel, Switzerland). Reactions were run in triplicate in three independent experiments. The relative expression of E-cadherin and vimentin were normalised to GAPDH. The primer sequences were shown in our previous study (Sun et al, 2012). All the relative expressions in control were set to 1 .

Western blotting. Protein extracts were resolved through 10\% SDS-polyacrylamide gel electrophoresis, transferred to polyvinylidene difluoride membranes (Bio-Rad, Berkeley, CA, USA), probed with antibody against human E-cadherin, vimentin (Santa Cruz, Santa Cruz, CA, USA), $\beta$-catenin, pEzrin Thr567 (Abcam, Cambridge, MA), Ezrin, pEzrin Tyr353, I $\kappa \mathrm{B} \alpha, \mathrm{p}-\mathrm{I} \kappa \mathrm{B} \alpha, \mathrm{ERK} 1 / 2$, p-ERK1/2, Akt, p-Akt (Ser473), ROCK1 (Cell Signaling Technology, CST, Danvers, MA, USA) or GAPDH (Proteintech, Chicago, IL, USA), and then with peroxidase-conjugated secondary antibody (Proteintech) and visualised by chemiluminescence (GE, Fairfield, CT, USA). The band densities were quantified by Gel-Pro analyser 4.0 (Media Cybernetics, Rockville, MD, USA). The band intensity values of E-cadherin, vimentin, Ezrin and ROCK1 were normalised to those of GAPDH. The ratios of phosphorylated target to its total protein values were also calculated.

Immunofluorescence staining. Cells were stained for immunofluorescence on coverslips. After fixation and permeabilisation, the cells were incubated with primary antibodies against E-cadherin, vimentin (Santa Cruz) or p65 (CST) and then incubated with rhodamine- or FITC-conjugated secondary antibodies (Invitrogen). The coverslips were counterstained with 4',6-diamidino-2-phenyl indole and imaged under a confocal microscope TCS SP5 (Leica, Solms, Germany). The images were merged with ImageJ software (National Institutes of Health, Betheseda, MD, USA).

Modified Boyden chamber assay. A total of $1 \times 10^{5}$ cells were plated into the upper chamber of a polycarbonate transwell filter chamber (Corning, NewYork, NY, USA) and incubated for $10 \mathrm{~h}$. For invasion assay, the upper chamber was coated with Matrigel (R\&D, Minneapolis, MN, USA) and incubated for $24 \mathrm{~h}$. Cells on the lower membrane surface were fixed in $4 \%$ paraformaldehyde, stained with crystal violet and counted (five random $100 \times$ fields per well). Three independent experiments were performed and the data are presented as the average \pm s.d.

Wound healing assay. A total of $1 \times 10^{6}$ cells were seeded in sixwell plates and grew until reaching $90 \%$ confluence. Linear wounds were created using pipette tips and then cells were cultured without serum. Wounds were observed and photographed at 0 and $10 \mathrm{~h}$.

Luciferase reporter assay. To evaluate the function of Ezrin in activating NF- $\kappa$ B, Ezrin siRNA was transfected in TSCC cells, and then pNF- $\kappa \mathrm{B}-\mathrm{luc}$, together with pRL-TK control vector or pTAL-luc, together with pRL-TK, were transfected into these cells. To confirm which phosphosite of Ezrin regulated the activity of NF$\kappa \mathrm{B}$, different Ezrin plasmids (WT or mutated) were co-transfected with pNF- $\kappa$ B-luc and pRL-TK control vector into HER-293 cells (low Ezrin expression). Luciferase activities were assayed using a luciferase assay kit (Promega, Madison, WI, USA).

Patients and tissue samples. Primary tongue carcinomas were obtained from 63 patients who were admitted to the Department of Oral and Maxillofacial Surgery of the Sun Yat-sen Memorial Hospital, Sun Yat-sen University, from January 2007 to January 2008. All the patients recruited into the present study did not receive radiotherapy or chemotherapy or any other treatment before and after operation, following a protocol approved by the ethics committee. All samples were collected with informed consent. The pathological sections for immunohistochemical assay were collected during surgery.

Immunohistochemistry. For immunohistochemistry, E-cadherin, vimentin (Santa Cruz), pEzrin Tyr353, p65 (CST) were used as primary antibodies for overnight incubation at $4{ }^{\circ} \mathrm{C}$. The sections were subsequently treated with secondary antibody, followed by further incubation with streptavidin-horseradish peroxidase complex. 
Diaminobenzidine (Dako) was used as a chromogen and sections were lightly counterstained with haematoxylin. In total, $5 \times 1000$ tumour cells were counted in each section. High expression: positive cells $>30 \%$; low expression: positive cells $<30 \%$.

Tumour xenografts. Tongue cancer SCC 9 cells that were infected with shGFP or shEzrin were injected subcutaneously into the armpit of the 5 -week-old BALB/c-nu mice ( $n=8$ per group), following a protocol approved by the ethics committee of Sun Yatsen University. When the xenografts were palpable (around $0.5 \mathrm{~cm}$ in diameter), intratumour injection of PBS or EGF at $0.02 \mathrm{mg} \mathrm{kg}^{-1}$ was performed bi-weekly for 5 consecutive weeks. Tumour growth was evaluated by monitoring tumour volume $(\mathrm{TV}=$ length $\times$ width $^{2} \times 0.5$ ) bi-weekly for 8 weeks. Then, tumour xenografts, as well as whole lung and liver tissues, were harvested, weighed and snap-frozen in liquid nitrogen. To evaluate in vivo metastasis, images of mice lungs and livers were acquired and portions of the lung and liver tissues were used for qRT-PCR for human hypoxanthine phosphorybosyl transferase expression (Sun et al, 2012). Cryosections ( $4 \mu \mathrm{m}$ ) were stained with haematoxylin and eosin and used for immunohistochemistry.

Statistics. All statistical analyses were performed using SPSS 17.0 (Armonk, NY, USA). The Student's $t$-test and $\chi^{2}$ test were used to analyse the relationship between Ezrin or NF- $\kappa$ B activation (nuclear p65) and clinicopathological characteristics. To measure the association between pairs of variables, Spearman's order correlations were run. Kaplan-Meier survival curves were plotted and log-rank test was performed. All experiments for cell cultures were performed at least in triplicate. Results were expressed as mean \pm s.d. $P<0.05$ was considered statistically significant.

\section{RESULTS}

Ezrin is phosphorylated by EGF, and reduction of Ezrin inhibits EGF-induced EMT in TSCC cells. The SCC9 and SCC25 cells grew in clusters and were round in shape with tight cell-cell junctions, whereas SCC9 and SCC25 cells treated with EGF displayed spindle shape and separated from one another (Supplementary Figure 1a). Immunofluorescence staining and western blotting demonstrated that the protein expression of E-cadherin decreased, whereas that of vimentin markedly increased in TSCC cells treated with EGF (Supplementary Figures $1 \mathrm{~b}$ and $\mathrm{c}$ ). Furthermore, E-cadherin and $\beta$-catenin were localised on and under the cell membrane in the EGF-untreated TSCC cells and localised in the cytoplasm in the EGF-treated TSCC cells (Supplementary Figures 1b). In addition, we examined the invasion and migration of EGF treated TSCC cells using Boyden chamber assays. After 24 or $10 \mathrm{~h}$ of culture, the invasion and migration increased by 7-5.1- and 8.4-7.4-fold in EGF-treated SCC9 and SCC25 cells, respectively, as compared with SCC9 and SCC25 cells (Supplementary Figure 1d). Taken together, our observation indicates that SCC9 and SCC25 cells treated with EGF have undergone EMT with enhanced invasiveness and motility.

To explore the role of Ezrin in EGF-induced EMT, we first detected the phosphorylated site of Ezrin in EGF-treated SCC9 and SCC25 cells. Remarkable upregulation of p-Ezrin Tyr353 and Thr567 were observed in EGF-treated SCC9 and SCC25 cells (Figure 1a). Then, we silenced Ezrin expression using RNA interference (Supplementary Figure 2a), and found that Ezrin siRNAs enhanced expression of E-cadherin and inhibited expression of vimentin in EGF-treated SCC9 and SCC25 cells, as shown by western blotting (Figure 1b). These were further confirmed at mRNA level by qRT-PCR (Supplementary Figures 2b). At the same time, Ezrin siRNAs reserved mesenchymal morphology of EGF-treated SCC9 and SCC25 cells. These cells began to grow in cluster and were round in shape (Figure 1c). Modified Boyden chamber assay demonstrated that Ezrin siRNAs suppressed the invasion and migration of EGF-treated SCC9 and SCC25 cells (Figure 1d). Wound healing assay also showed that downexpression of Ezrin suppressed the motility of EGF-treated TSCC cells (Supplementary Figure 2c). These data suggest that reduction of Ezrin could inhibit EGF-induced EMT in TSCC cells.

Phosphorylation of Akt and Ezrin Tyr353 is responsible for activation of NF- $\kappa$ B in EGF-treated TSCC cells. It has been reported that several signal pathways are involved in activating Ezrin, including Akt, ERK1/2 and ROCK1. We detected the activations of Akt, ERK1/2 and ROCK1 in EGF-treated TSCC cells and found that Akt and ERK1/2 were phosphorylated and the expression of ROCK1 was upregulated (Supplementary Figure 3a). Then, we pretreated these TSCC cells with LY294002 (Akt inhibitor), PD98059 (ERK1/2 inhibitor) or Y27632 (ROCK1 inhibitor) and investigated the phosphorylation of Ezrin Tyr353 and Thr567. Phosphorylation of Ezrin Tyr353 was inhibited by LY294002, but not by PD98059 and Y27632. The three inhibitors have no effects on phosphorylation of Ezrin Thr567 (Figure 2a). These data indicated that phosphorylation of Ezrin Tyr353 was mediated by Akt in EGF-treated TSCC cells.

Immunofluorescence assay showed that p65 translocated to TSCC cell nuclear after EGF treatment (Supplementary Figure 3b), suggesting that NF- $\kappa \mathrm{B}$ was activated by EGF. To explore the key mediator in activating NF- $\kappa \mathrm{B}$, we pretreated TSCC cells with LY294002, PD98059 or Y27632 before EGF treatment. As shown by immunofluorescence assay, p65 translocation to cell nuclear was inhibited by Akt inhibitor and NF- $\kappa$ B inhibitor (BAY and JSH), but not by ERK and ROCK1 inhibitors (Supplementary Figure 3b). Taken together, Akt activated Ezrin Tyr353 and NF- $\kappa$ B in EGFtreated TSCC cells.

To demonstrate the relationship between Ezrin and NF- $\kappa$ B, we silenced Ezrin expression in EGF-treated TSCC cells and examined $\mathrm{NF}-\kappa \mathrm{B}$ activity. We found that Ezrin siRNAs significantly suppressed phosphorylation of $\mathrm{I} \kappa \mathrm{B} \alpha$ (Figure 2b) and p65 translocation to nuclear (Figure 2c) in EGF-treated TSCC cells. At the same time, luciferase reporter assay showed that knockdown of Ezrin suppressed NF- $\kappa \mathrm{B}$ activities in EGF-treated TSCC cells (Figure 2d; $P<0.01$ ). These results indicated that Ezrin regulated the activation of NF- $\kappa \mathrm{B}$ in EGF-treated TSCC cells. To further confirm the functional site of Ezrin, TSCC cells were highly expressed with Ezrin or mutated Ezrin (Ezrin Y353F, Ezrin T567A) (kind gifts from Dr Arpin M). Luciferase reporter assay showed that NF- $\kappa \mathrm{B}$ activity was enhanced when EGF-treated TSCC cells were transfected with WT Ezrin or Ezrin T567A $(P<0.05)$, but could not be enhanced when cells were transfected with Ezrin Y353F (Supplementary Figure 3c). Furthermore, we transfected these plasmids into HER-293 cells with low Ezrin expression. Luciferase reporter assay also showed that Ezrin Y353F could not enchance NF- $\kappa \mathrm{B}$ activity (Figure 2e). In conclusion, these results indicated that phosphorylation of Akt and Ezrin Tyr353 is responsible for the activation of NF- $\kappa \mathrm{B}$ in EGF-treated TSCC cells.

EGF induces EMT through Akt/Ezrin/NF- $\kappa$ B pathway in TSCC cells. To determine the signal pathway involved in EGF-induced EMT in TSCC cells, we pretreated the cells with inhibitors of Akt or NF- $\kappa \mathrm{B}$ and then transfected Ezrin siRNA. We found that Akt and NF- $\kappa \mathrm{B}$ inhibitors, as well as Ezrin siRNA, blocked EGFinduced EMT in TSCC cells. Expression of E-cadherin in TSCC cells was not inhibited and the expression of vimentin was not enhanced by EGF (Figure 3a). However, ERK and ROCK1 inhibitors could not block EGF-induced EMT in TSCC cells (Supplementary Figure 4a), suggesting that activation of the Akt/ Ezrin/NF- $\kappa \mathrm{B}$ pathway, but not ERK and ROCK1, was important for EGF-induced EMT in TSCC cells. At the same time, Akt and NF- $\kappa \mathrm{B}$ inhibitors impaired the mesenchymal phenotype of EGF-treated TSCC cells (Figure 3b), and suppressed invasion and 
A

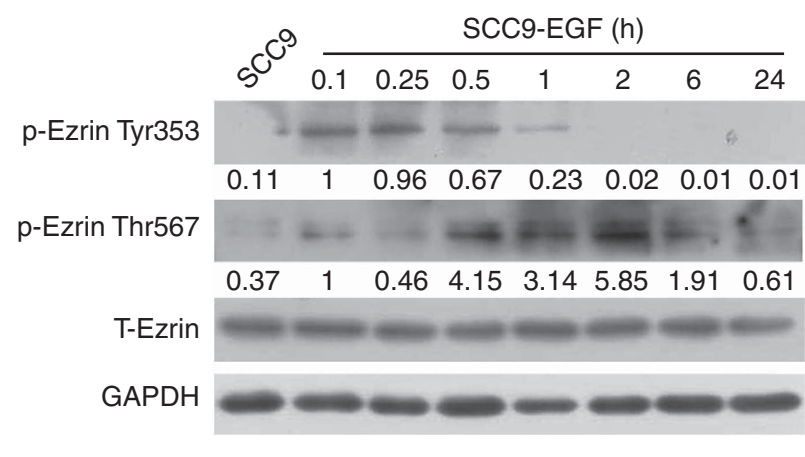

B

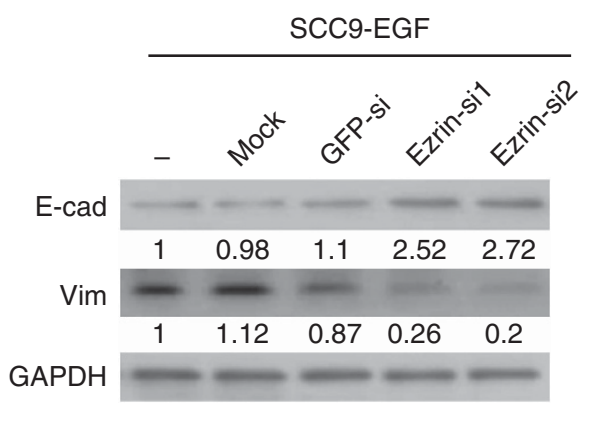

C

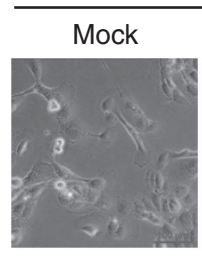

D

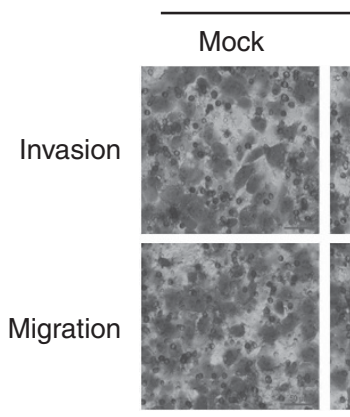

SCC9-EGF
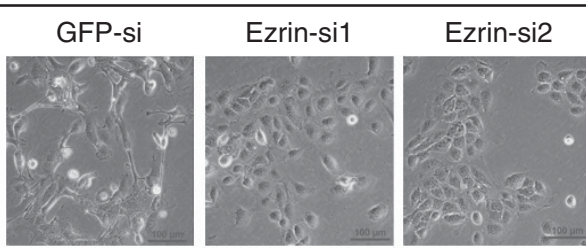

SCC9-EGF

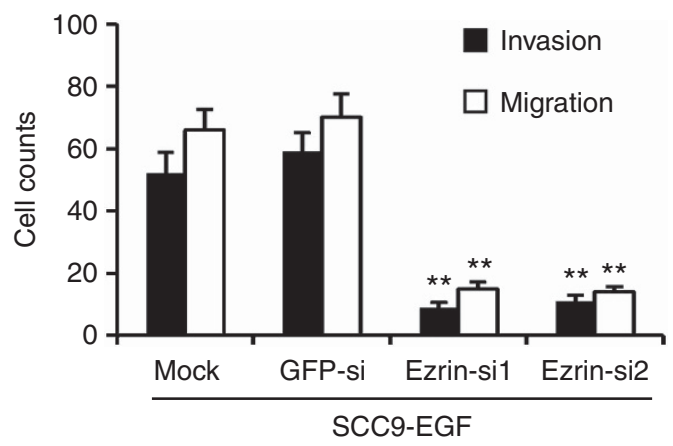

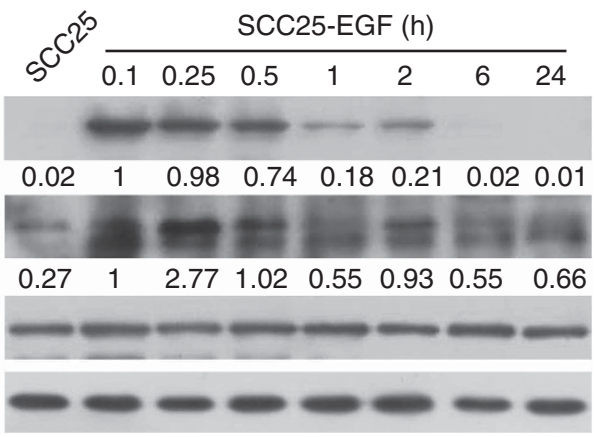

SCC25-EGF

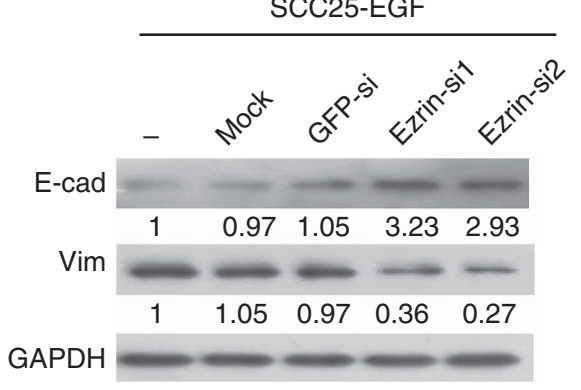

SCC25-EGF

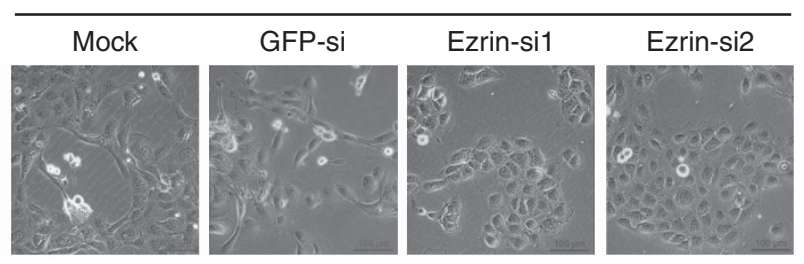

SCC25-EGF
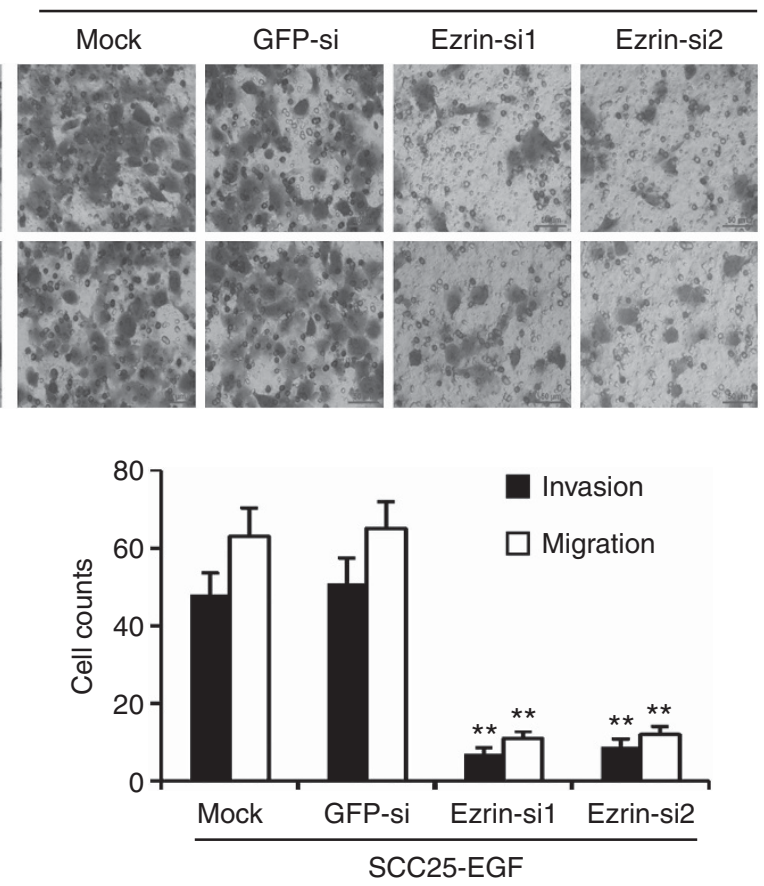

Figure 1. Ezrin is phosphorylated by EGF, and reduction of Ezrin inhibits EGF-induced EMT of SCC9 and SCC25 cells. (A) Western blotting showed that Ezrin Tyr 353 and Thr 567 were phosphorylated in EGF-treated SCC9 and SCC25 cells. Glyceraldehyde 3-phosphate dehydrogenase (GAPDH) was used as an internal control. The ratios of phosphorylated target to its total protein values were calculated. (B) Western blotting showed that transfection with Ezrin siRNA enhanced expression of E-cadherin (E-cad) and inhibited expression of vimentin (Vim) in EGF-treated SCC9 and SCC25 cells. The band intensity values of E-cadherin and vimentin were normalised to those of GAPDH. (C) Transfection with Ezrin siRNA inhibited mesenchymal morphology in EGF-treated SCC9 and SCC25 cells. Scale bar: $100 \mu \mathrm{m}$. (D) Modified Boyden chamber assays demonstrated transfection with Ezrin siRNA inhibited invasion and migration of EGF-treated SCC9 and SCC25 cells. Scale bar: $50 \mu \mathrm{m}$. ${ }^{\star \star} P<0.01$ vs mock. 
A

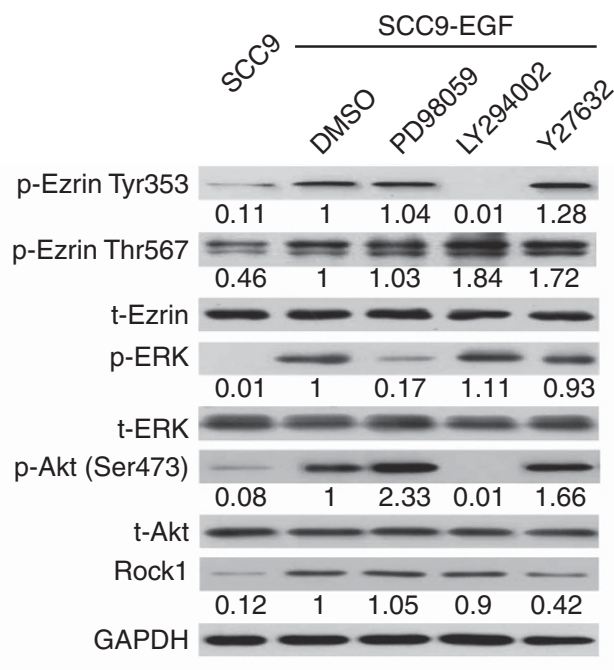

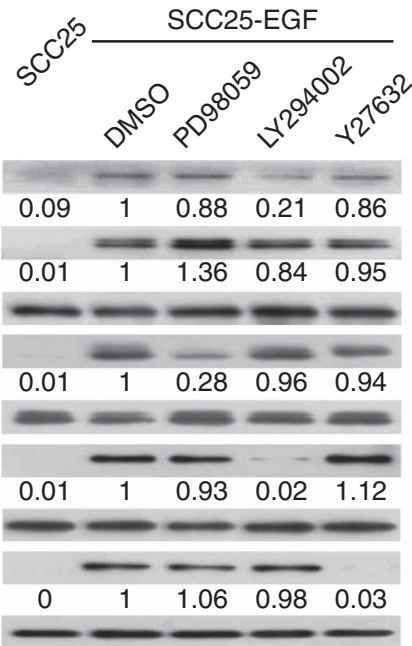

B

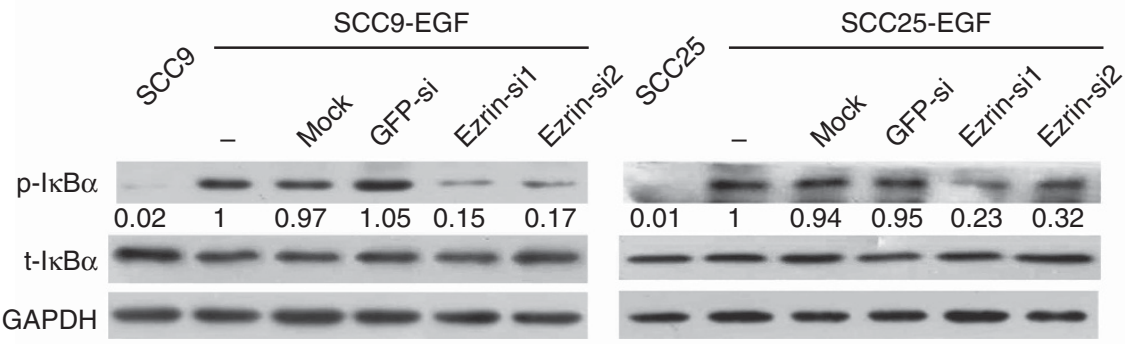

C

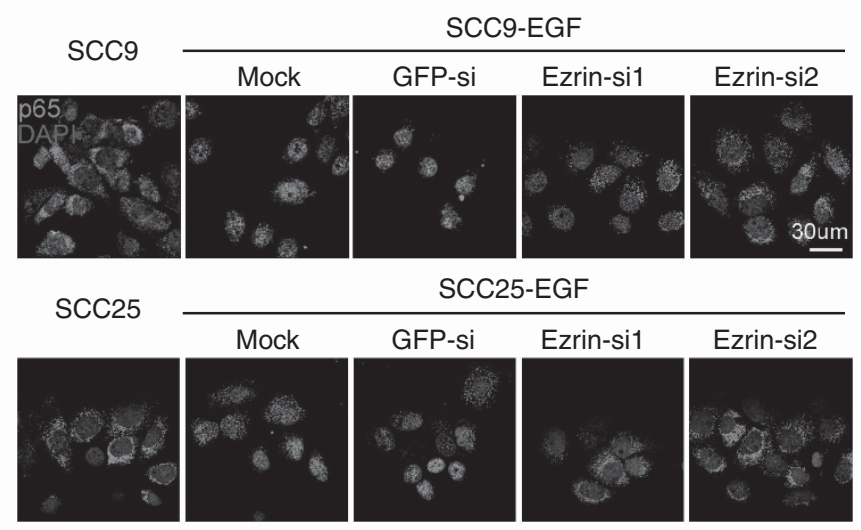

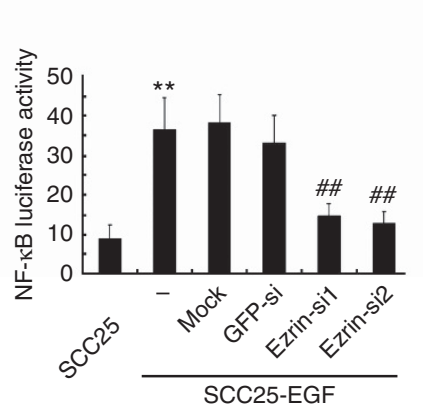

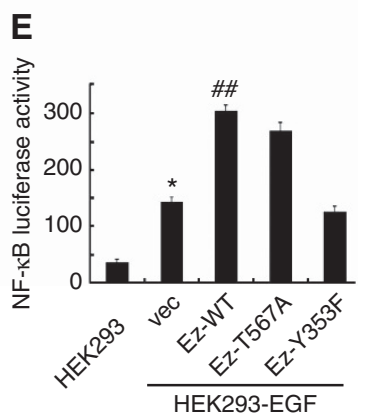

Figure 2. Phosphorylation of Akt and Ezrin Tyr353 is responsible for activation of NF- $\kappa$ B in EGF-treated SCC9 and SCC25 cells. (A) Western blotting showed that phosphorylation of Ezrin Tyr353 was inhibited by Akt inhibitor (LY294002, $20 \mu \mathrm{M})$ but not EKR1/2 (PD98059, $20 \mu \mathrm{M})$ and ROCK1 (Y27632, $20 \mu \mathrm{m}$ ) inhibitors, and these three inhibitors had no effect on phosphorylation of Ezrin Thr567 in EGF-treated SCC9 and SCC25 cells.

(B) Western blotting showed that transfection with Ezrin siRNA inhibited phosphorylation of $I_{\kappa} \mathrm{B} \alpha$ in EGF-treated SCC9 and SCC25 cells. The band intensity value of ROCK1 was normalised to those of GAPDH. The ratios of phosphorylated target to its total protein values were also calculated. (C) Immunofluorescence staining demonstrated that Ezrin siRNA inhibited p65 nuclear translocation in EGF-treated cells. Scale bar: $30 \mu \mathrm{m}$. p65: red; nuclear: green; merged: yellow. (D) Luciferase reporter assay showed that Ezrin siRNA inhibited NF- $\kappa$ B activity in EGF-treated cells. ${ }^{\star \star} P<0.01$ vs SCC9 or SCC25 cells. ${ }^{\# \#} P<0.01$ vs mock. (E) Luciferase reporter assay showed that Ezrin Tyr353 was responsible for activation of NF- $k B$ in EGF-treated HER-293 cells. vec: pcDNA3.1; Ez-WT: wild-type Ezrin; Ez-T567A: Ezrin with Thr567 mutated to Ala; Ez-Y353F: Ezrin with Tyr567 mutated to Phe.

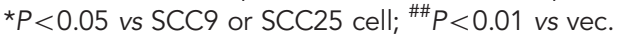


A
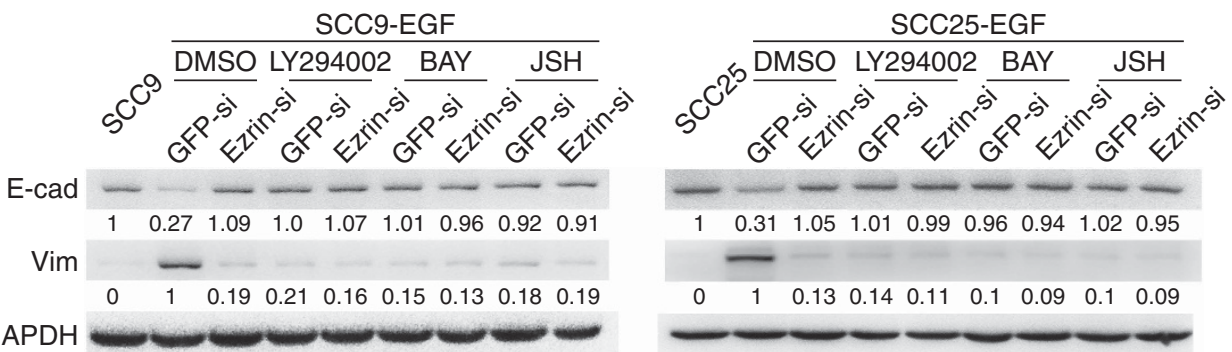

B
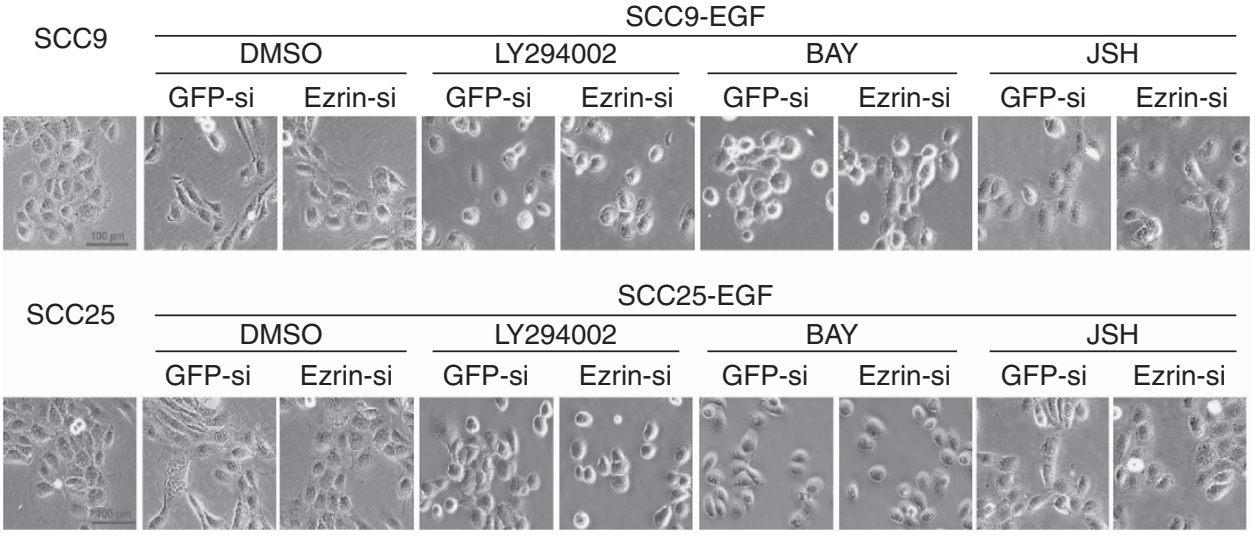

C

\section{Scc9}

SCC9-EGF
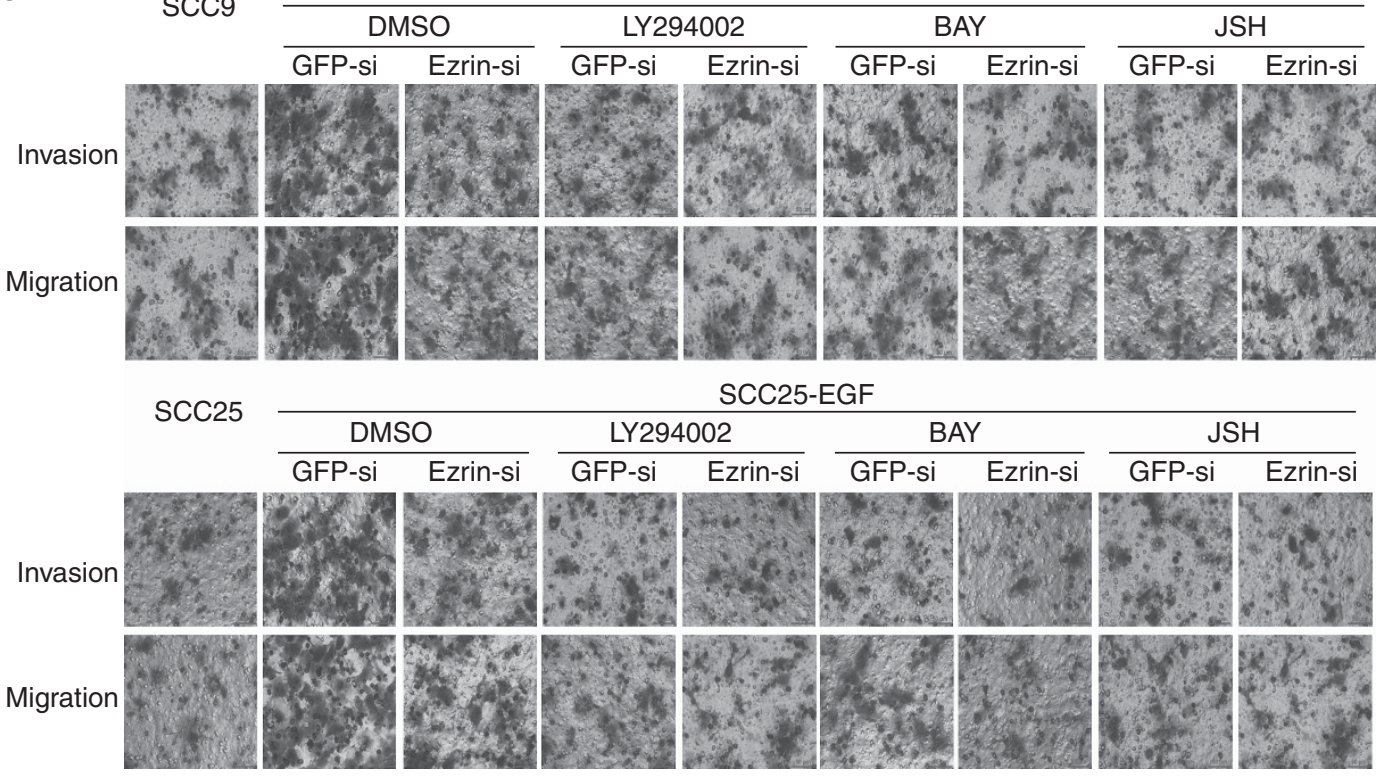

SCC25-EGF

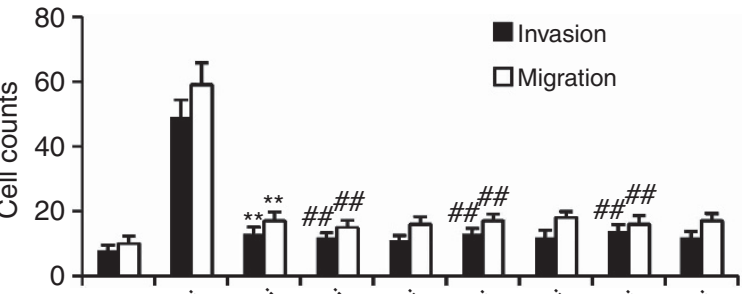

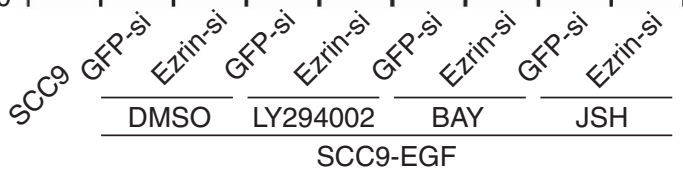

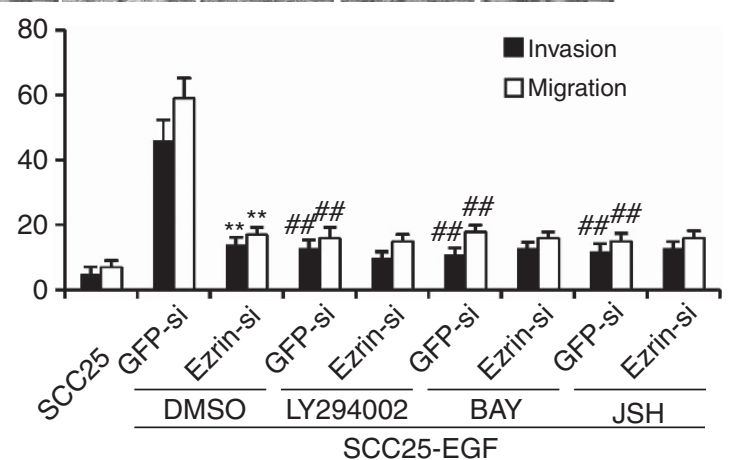

Figure 3. Epidermal growth factor induces EMT through Akt/Ezrin/NF- $\kappa$ B pathway in SCC9 and SCC25 cells. (A) Western blotting showed that transfection with Ezrin siRNA and pre-treating Akt inhibitor (LY294002), NF- $k$ B inhibitor (Bay 11-7082, $10 \mu \mathrm{m}$ and JSH-23, $20 \mu \mathrm{m}$ ) enhanced the expression of E-cadherin (E-cad) and inhibited expression of vimentin (Vim) in EGF-treated SCC9 and SCC25 cells. GAPDH was used as an internal control. (B) Transfection with Ezrin siRNA and pre-treating Akt inhibitor, NF-kB inhibitor reversed mesenchymal morphology of EGF-treated SCC9 and SCC25 cells. Scale bar: $100 \mu \mathrm{m}$. (C) Modified chamber assay showed that transfection with Ezrin siRNA and pre-treating Akt inhibitor, NF- $k$ B inhibitor inhibited invasion and migration in EGF-treated SCC9 and SCC25 cells. Scale bar: $50 \mu \mathrm{m}$. ${ }^{\star \star} P<0.01$ vs GFP-si; ${ }^{\# \#} P<0.01$ vs DMSO. 
migration of these cells (Figure 3c). Wound healing assay also showed that blocking the Akt/Ezrin/NF- $\kappa \mathrm{B}$ pathway could suppress the motility of EGF-treated SCC9 and SCC25 cells (Supplementary Figure $4 \mathrm{~b}$ ).

Reduction of Ezrin inhibits metastasis of EGF-treated TSCC xenografts. As reduction of Ezrin inhibited EMT of EGF-treated TSCC cells in vitro, we further assessed its effect on tumour growth and metastasis in vivo. Ezrin was stably downregulated in SCC9 cells by infected with lentivirus carrying Ezrin shRNA (shEzrin) (Supplementary Figure 5a). As shown in Supplementary Figures 5b and $c$, downexpression of Ezrin did not significantly change tumour growth or body weight of the BALB/c-nu mice inoculated with SCC9 cells.

Although injection of EGF into SCC9 xenografts did not obviously change the primary tumour size, it increased the number of mice with lung and liver metastasis, and silenced Ezrin expression suppressed these metastasis (Figure 4a). Haematoxylin and eosin staining also showed that EGF injection led to more massive metastasis in the lungs and livers of the mice as compared with PBS injection, and silenced Ezrin expression suppressed these metastasis (Figure $4 \mathrm{~b}$ ). Furthermore, the average lung weight of SCC9 tumour-bearing mice injected with EGF was reduced by silencing Ezrin expression (Figure $4 c ; P<0.01$ ). The number of metastasised tumour cells in the lung and the liver, quantified by qRT-PCR for human hypoxanthine phosphorybosyl transferase (hHPRT) in tumour-bearing mice injected with EGF, was reduced by $80 \%$ and $90 \%$, respectively, by silencing Ezrin expression (Figure $4 \mathrm{~d} ; \quad P<0.01)$. Collectively, these data suggested that reduction of Ezrin significantly suppressed the metastasis of SCC9 xenografts injected with EGF.

Moreover, immunohistochemical staining revealed that reduction of Ezrin inhibited downexpression of E-cadherin and upexpression of vimentin, and reduced nuclear p65 expression by more than $75 \%$ in tumour-bearing mice injected with EGF (Figure $4 \mathrm{e}$ and Supplementary Figure 5d; $P<0.01$ ). These findings suggest that reduction of Ezrin inhibits EMT and metastasis of TSCC in vivo probably via inhibiting NF- $\kappa \mathrm{B}$ activity in tumourbearing mice injected with EGF.

Activation of Ezrin and NF- $\kappa$ B is associated with metastasis and poor patient survival in TSCCs. We further evaluated the clinical significance of Ezrin and NF- $\kappa \mathrm{B}$ activation in metastasis and patient prognosis of TSCCs. Immunohistochemical staining demonstrated that vimentin, pEzrin Tyr353 expression and nuclear p65 expression were lower, and E-cadherin expression was higher in low metastatic TSCCs compared with that in high metastatic TSCCs (Figure 5a). In addition, Spearman's order correlation analysis showed that pEzrin Tyr353 expression in TSCC was positively correlated with nuclear p65 expression level (Figure $5 \mathrm{~b} ; r_{\mathrm{s}}=0.74, P<0.001$ ), and pEzrin Tyr353, nuclear p65 expression in TSCCs was positively correlated with vimentin expression (Figure 5b; $r_{\mathrm{s}}=0.57, P<0.001$ and $r_{\mathrm{s}}=0.51, P<0.001$, respectively).

Next, we analysed the association of pEzrin Tyr353 and nuclear p65 expression with clinicopathological status of TSCC patients (Table 1). No significant correlation was observed among pEzrin Tyr353, nuclear NF- $\kappa$ B p65, E-cadherin or vimentin expression and sex or age. However, pEzrin Tyr353, nuclear p65, E-cadherin and vimentin levels were closely associated with lymph node metastasis and clinical stage of the patients. Tumours with lymph node metastasis or high clinical stage expressed high levels of Ezrin Tyr353, nuclear p65 and vimentin, suggesting that pEzrin Tyr353, nuclear p65 and vimentin upregulations were associated with tumour progression. On the contrary, E-cadherin expression was negatively correlated with lymph node metastasis and clinical stage of TSCCs.
Furthermore, we evaluated the correlation between pEzrin Tyr353, nuclear p65 expression, E-cadherin/vimentin expression and survival of the patients. Patients with low expression of pEzrin Tyr353 or nuclear p65 in tumours survived significantly longer than those with high pEzrin Tyr353 or nuclear p65 expression in tumours (Figure $5 c ; P=0.006$ or $P=0.003$, respectively). The cumulative survival rate up to 60 months was $69 \%$ or $72 \%$ in patients with low pEzrin Tyr353 or nuclear p65 expression, respectively, while only $38 \%$ or $35 \%$ in those with high pEzrin Tyr353 or nuclear p65 expression, respectively. Furthermore, TSCC patients with high E-cadherin/low vimentin expression had better survival than those with low E-cadherin/high vimentin expression $(P=0.001)$. These data suggest that activation of Ezrin and NF- $\kappa \mathrm{B}$ is positively correlated with tumour staging and may have a role in the progression of TSCCs.

\section{DISCUSSION}

In the current study, we demonstrate that Akt/Ezrin Tyr353/NF- $\kappa \mathrm{B}$ pathway is critical for EGF-induced EMT, and reduction of Ezrin reverses mesenchymal features of EGF-treated TSCC cells and represses metastasis of TSCC via inhibiting NF- $\kappa \mathrm{B}$ activity. Furthermore, Ezrin and NF- $\kappa \mathrm{B}$ activities are positively associated with lymph node metastasis of TSCC patients, and high activities indicate poor prognosis of these patients.

Dysregulation of Ezrin has been well documented in many types of human malignancies (Arpin et al, 2011), and previous studies have shown that overexpression and activation of Ezrin alter cell shape, adhesion, motility and apoptosis and correlate with the invasion and metastasis of many human cancers (Khanna et al, 2004; Elliott et al, 2005; Srivastava et al, 2005; Chiang et al, 2008; Chuan et al, 2009; Kuo et al, 2009; Vanacker et al, 2011). Phosphorylation of Ezrin is required for conformational activation and for signal transduction, and Thr567 and Tyr353 are the most common phosphorylated sites (Arpin et al, 2011). Activation of Ezrin is involved in several pathways, such as Rho-, Src-, PKC-, EGF- and HGF-activated pathways (Crepaldi et al, 1997; Srivastava et al, 2005; Chiang et al, 2008; Ren et al, 2008; Chen et al, 2011). Furthermore, it has been reported that several signal pathways are involved in activating Ezrin, including Akt, ERK1/2 and ROCK1 (Elliott et al, 2005; Sizemore et al, 2007). However, in this study, we found that Akt pathway, but not ERK1/2 and ROCK1, was essential for EGF-induced activation of Ezrin Tyr353. This activation may be an indirect process and other signalling molecules may have a role between Akt and Ezrin as Akt is a serine/threonine kinase. One previous study showed that Ezrin was an upstream signalling molecule of Akt activation (Gautreau et al, 1999). Thus, we need to address this issue in further study. Furthermore, luciferase reporter assay demonstrated that only phosphorylation of Ezrin Tyr353, excluding phosphorylation of Ezrin Thr567, was required for the activation of NF- $\kappa$ B induced by EGF, indicating that Ezrin regulates EGF-induced EMT and metastasis via activating NF- $\kappa \mathrm{B}$. Phosphorylated Ezrin activates $\mathrm{NF}-\kappa \mathrm{B}$ and then NF- $\kappa \mathrm{B}$ triggers a transcription programme that lead to EMT. This process usually takes days, as EMT is a complex transcription programme that involves multiple pathway and transcription factors. Ezrin siRNAs can significantly inhibit phosphorylation of $\mathrm{I} \kappa \mathrm{B} \alpha$ and we speculate that phosphorylated Ezrin might activate NF- $\kappa \mathrm{B}$ by directly or indirectly phosphorylate $\mathrm{I} \kappa \mathrm{B} \alpha$, the inhibitor of NF- $\kappa \mathrm{B}$ (Supplementary Figure 6).

Epithelial-mesenchymal transition is believed to be a crucial programme in cancer metastasis and EGF has been reported to be an important EMT inducer (Hardy et al, 2010; Al Moustafa et al, 2012). For example, EGF induces ovarian cancer cell EMT and invasion, migration by activating the ERK1/2 and PI3K/Akt 
A
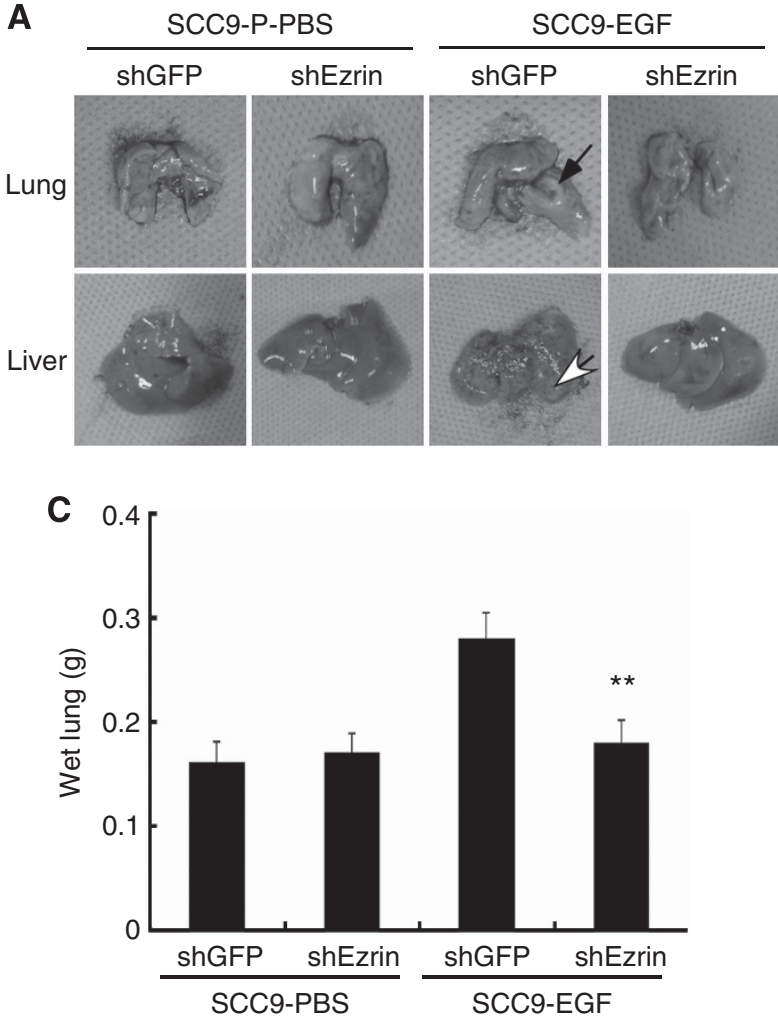

E
B

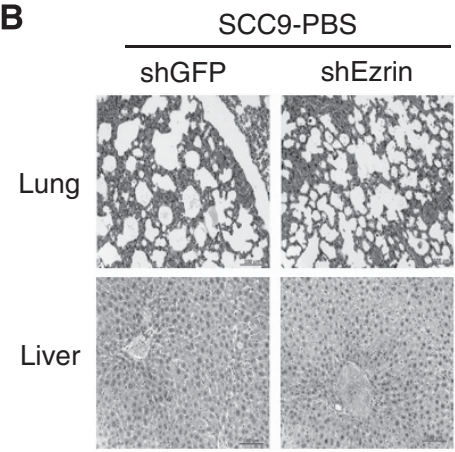

D
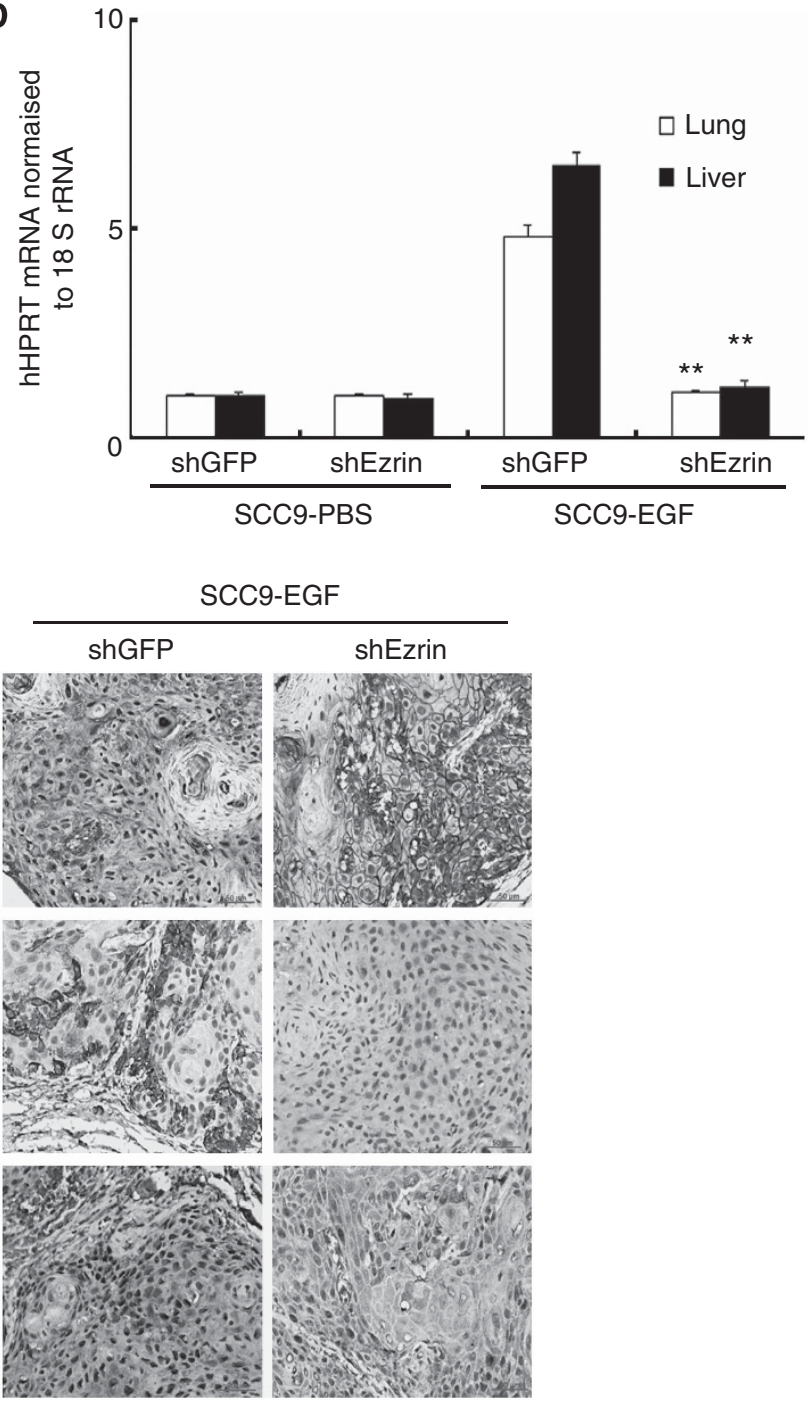

Figure 4. Reduction of Ezrin inhibits metastasis of EGF-injected SCC9 xenografts of BALB/c-nu mice. (A) Tissue images and (B) haematoxylin and eosin staining of paraffin sections for the lungs (upper) and livers (lower) of the tumour-bearing mice. Arrows: tumour; scale bar: $100 \mu \mathrm{m}$. (C) Mean \pm s.d. wet lung weight of tumour-bearing mice ( $n=8$ per group). (D) Expression of human HPRT mRNA relative to mouse $18 \mathrm{~S}$ rRNA, in the lungs and livers of the tumour-bearing mice, was determined by qRT-PCR. ${ }^{\star \star} P<0.01$ vs shGFP. (E) Immunohistochemical staining illustrated that reduction of Ezrin enhanced E-cadherin expression, inhibited vimentin expression and p65 nuclear expression of EGF-injected SCC9 xenografts. Scale bar: $50 \mu \mathrm{m}$. shEzrin, Ezrin shRNA.

pathways and upregulating Snail, Slug and ZEB1 (Chai et al, 2012). However, another study demonstrated that EGF promoted EMT by activating Akt pathway, but not ERK1/2 pathway (Gan et al, 2010). In the present study, our data also demonstrated that activation of Akt, but not ERK1/2, mediated the EGF-induced EMT. Epithelialmesenchymal transition-induced by EGF is mainly due to
Akt-mediated activation of Ezrin Tyr353 and NF- $\kappa$ B. Thus, we identified Akt/Ezrin/NF- $\kappa$ B pathway as an important pathway in regulating EGF-induced EMT and metastasis in TSCC cells. This is supported by the fact that $\mathrm{NF}-\kappa \mathrm{B}$ can promote and maintain invasive phenotype, repress epithelial marker expression and induce mesenchymal marker expression (Min et al, 2008). 
A
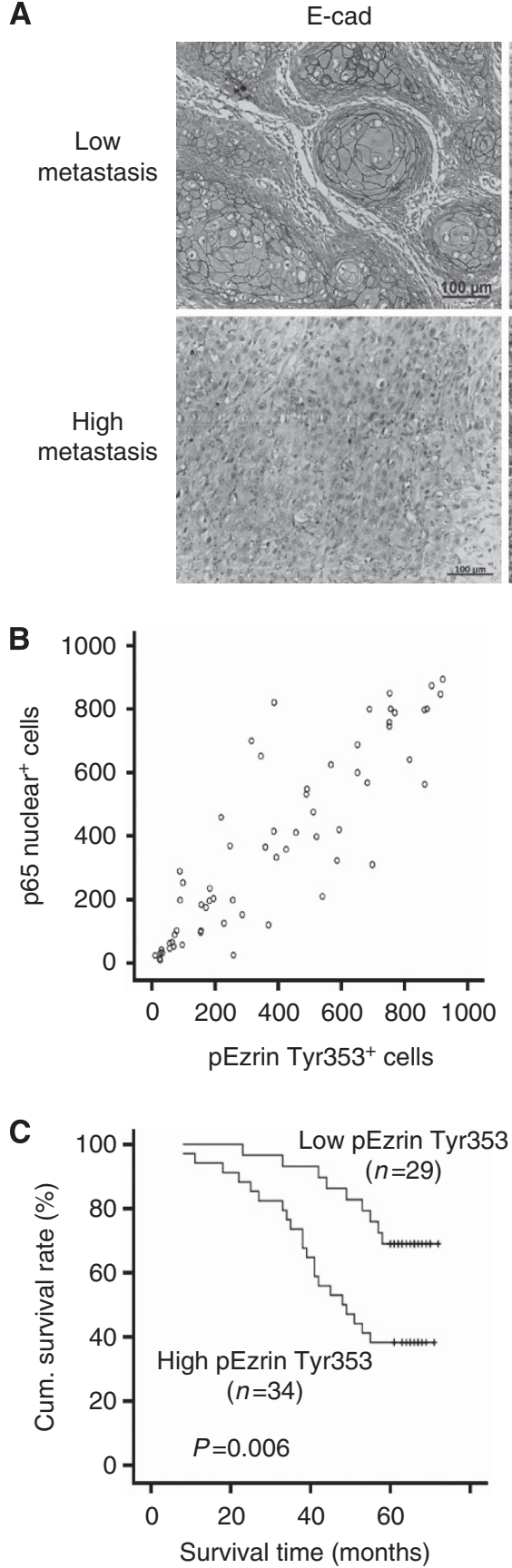
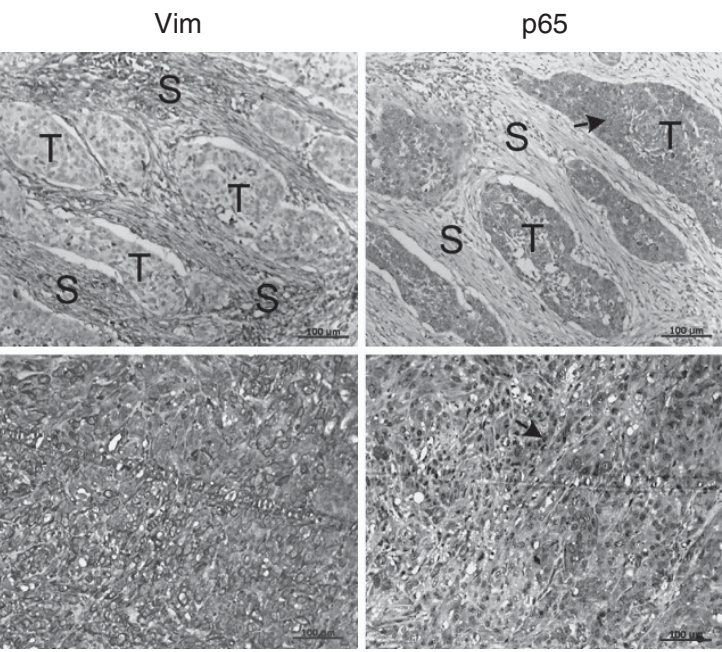
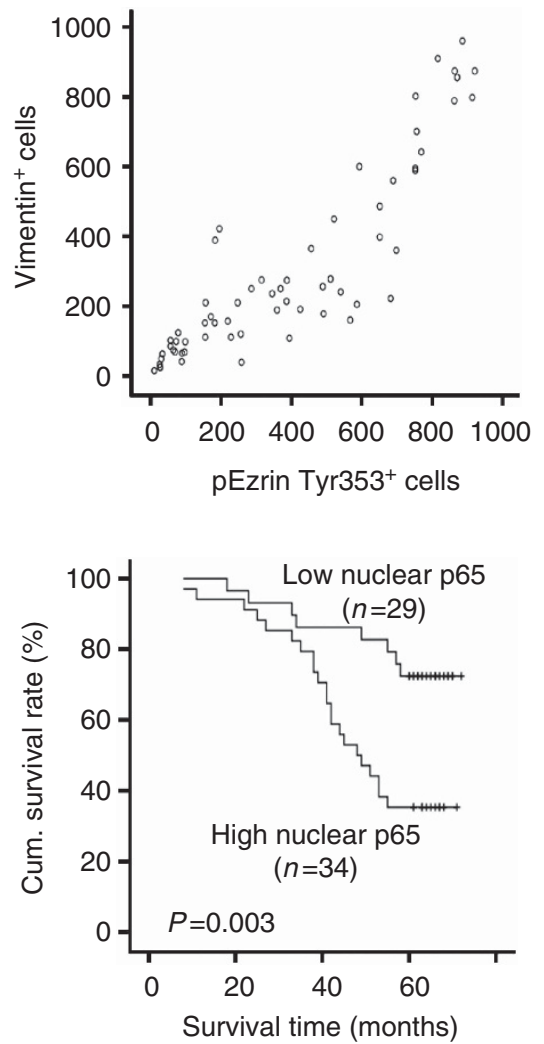
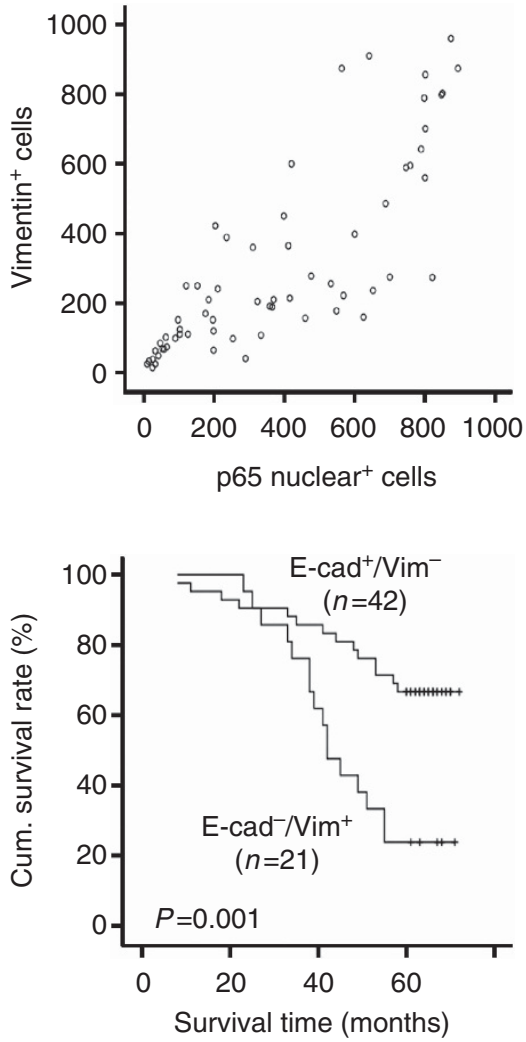

Figure 5. Activation of Ezrin and NF- $\kappa$ B correlates with metastasis and poor patient survival in TSCCs. (A) Immunohistochemical staining for E-cadherin (E-cad), vimentin (Vim), pEzrin Tyr353 and NF- $\kappa$ B p65 were demonstrated in TSCCs. Scale bar: $100 \mu \mathrm{m}$. T, tumour; S, stroma. Arrows indicate p65 staining. P65 was expressed in the cytoplasm in low metastatic TSCCs and translocated to cell nuclear in high metastatic TSCCs. (B) Associations between nuclear p65 (left), Vim (middle) expression and pEzrin Tyr353 expression, and between Vim (Baumgartner et al, 2006) and nuclear p65 in TSCCs were analysed with Spearman's order correlation. (C) Kaplan-Meier survival curves for TSCC patients plotted on pEzrin Tyr353 (left), nuclear p65 (middle) and E-cad/Vim (Baumgartner et al, 2006) expression, and survival difference was analysed by log-rank test. High expression: positive cells $>30 \%$; low expression: positive cells $<30 \%$.

Finally, our findings demonstrate that expression, activation of Ezrin and activation of NF- $\kappa$ B have pivotal role in EMT and cancer metastasis of TSCC. Cancer metastasis is a major issue of treatment in the majority of human tumours, including TSCC (Gupta and Massagué, 2006), and EMT of the cancer cells is known to be the essential initiation for metastasis. We observed that low E-cadherin expression, high vimentin expression, activation of Ezrin Tyr353 and NF- $\kappa \mathrm{B}$ in clinical TSCC samples are associated with metastasis, and poor patient prognosis. Low expression of Ezrin reverses mesenchymal features of TSCC cells induced by EGF.
In vivo, downregulation of Ezrin expression inhibits activation of NF- $\kappa \mathrm{B}$ of cancer cells in EGF-treated TSCC xenografts, and reverses EMT of cancer cells and metastasis of these TSCC xenografts. Therefore, reduction of Ezrin may provide novel therapeutic strategy against metastasis of tongue cancers.

In summary, our study indicates that Ezrin and NF- $\kappa \mathrm{B}$ regulate EGF-induced EMT and cancer metastasis, and consequently have an important role in the development of TSCC. Our results provide a strong rationale for their potential use as therapeutic targets in metastatic tongue cancers. 


\begin{tabular}{|c|c|c|c|c|c|c|c|c|c|c|c|c|}
\hline \multirow[b]{2}{*}{ Characteristic } & \multicolumn{2}{|c|}{ pEzrin Tyr353 (\%) } & \multicolumn{3}{|c|}{ Nuclear p65 (\%) } & \multicolumn{3}{|c|}{ E-cadherin (\%) } & \multicolumn{3}{|c|}{ Vimentin (\%) } & \multirow[b]{2}{*}{$P$-value } \\
\hline & $\begin{array}{c}\text { No. of } \\
\text { low/ - } \\
\text { expression }\end{array}$ & $\begin{array}{c}\text { No. of } \\
\text { high } \\
\text { expression }\end{array}$ & $P$-value & $\begin{array}{c}\text { No. of } \\
\text { low/ - } \\
\text { expression }\end{array}$ & $\begin{array}{c}\text { No. of } \\
\text { high } \\
\text { expression }\end{array}$ & $P$-value & $\begin{array}{c}\text { No. of } \\
\text { low/ - } \\
\text { expression }\end{array}$ & $\begin{array}{c}\text { No. of } \\
\text { high } \\
\text { expression }\end{array}$ & $P$-value & $\begin{array}{c}\text { No. of } \\
\text { low/ - } \\
\text { expression }\end{array}$ & $\begin{array}{c}\text { No. of } \\
\text { high } \\
\text { expression }\end{array}$ & \\
\hline $\begin{array}{l}\text { Sex } \\
\text { Male } \\
\text { Female }\end{array}$ & $\begin{array}{l}16(45.7) \\
13(46.4)\end{array}$ & $\begin{array}{l}19(54.3) \\
15(53.6)\end{array}$ & 0.514 & $\begin{array}{l}15(42.9) \\
14(50.0)\end{array}$ & $\begin{array}{l}20(57.1) \\
14(50.0)\end{array}$ & 0.725 & $\begin{array}{l}11(31.4) \\
10(35.7)\end{array}$ & $\begin{array}{l}24(68.6) \\
18(64.3)\end{array}$ & 0.318 & $\begin{array}{l}24(68.6) \\
18(64.3)\end{array}$ & $\begin{array}{l}11(31.4) \\
10(35.7)\end{array}$ & 0.318 \\
\hline $\begin{array}{l}\text { Age (years) } \\
<50 \\
\geqslant 50\end{array}$ & $\begin{array}{l}12(41.3) \\
17(50.0)\end{array}$ & $\begin{array}{l}17(58.7) \\
17(50.0)\end{array}$ & 0.617 & $\begin{array}{l}13(44.8) \\
16(47.1)\end{array}$ & $\begin{array}{l}16(55.2) \\
18(52.9)\end{array}$ & 0.501 & $\begin{array}{r}9(31.0) \\
12(35.3)\end{array}$ & $\begin{array}{l}20(69.0) \\
22(64.7)\end{array}$ & 0.412 & $\begin{array}{l}20(69.0) \\
22(64.7)\end{array}$ & $\begin{array}{r}9(31.0) \\
12(35.3)\end{array}$ & 0.412 \\
\hline $\begin{array}{l}\text { Metastasis } \\
\text { N0 } \\
\text { N1-N2 }\end{array}$ & $\begin{array}{r}23(60.5) \\
6(24.0)\end{array}$ & $\begin{array}{l}15(39.5) \\
19(76.0)\end{array}$ & 0.010 & $\begin{array}{r}24(63.2) \\
5(20.0)\end{array}$ & $\begin{array}{l}14(36.8) \\
20(80.0)\end{array}$ & 0.007 & $\begin{array}{r}5(13.2) \\
16(64.0)\end{array}$ & $\begin{array}{r}33(86.8) \\
9(36.0)\end{array}$ & 0.001 & $\begin{array}{r}33(86.8) \\
9(36.0)\end{array}$ & $\begin{array}{r}5(13.2) \\
16(64.0)\end{array}$ & 0.001 \\
\hline $\begin{array}{l}\text { Clinical stage } \\
\text { I, II } \\
\text { III, IV }\end{array}$ & $\begin{array}{l}19(63.3) \\
10(30.3)\end{array}$ & $\begin{array}{l}11(36.7) \\
23(69.7)\end{array}$ & 0.018 & $\begin{array}{l}18(60.0) \\
11(33.3)\end{array}$ & $\begin{array}{l}12(40.0) \\
22(66.7)\end{array}$ & 0.026 & $\begin{array}{c}2(6.7) \\
19(57.6)\end{array}$ & $\begin{array}{l}28(93.3) \\
14(42.4)\end{array}$ & 0.001 & $\begin{array}{l}28(93.3) \\
14(42.4)\end{array}$ & $\begin{array}{c}2(6.7) \\
19(57.6)\end{array}$ & 0.001 \\
\hline $\begin{array}{l}\text { Status } \\
\text { Survival } \\
\text { Death }\end{array}$ & $\begin{array}{r}20(60.6) \\
9(33.3)\end{array}$ & $\begin{array}{l}13(39.4) \\
21(66.7)\end{array}$ & 0.029 & $\begin{array}{r}21(63.6) \\
8(26.7)\end{array}$ & $\begin{array}{l}12(36.4) \\
22(73.3)\end{array}$ & 0.007 & $\begin{array}{r}5(15.2) \\
16(53.3)\end{array}$ & $\begin{array}{l}28(84.8) \\
14(46.7)\end{array}$ & 0.003 & $\begin{array}{l}28(84.8) \\
14(46.7)\end{array}$ & $\begin{array}{r}5(15.2) \\
16(53.3)\end{array}$ & 0.003 \\
\hline
\end{tabular}

\section{ACKNOWLEDGEMENTS}

This work was supported by grants to WC from National Natural Science Foundation of China (81172563), Natural Science Foundation of Guangdong Province (S2011010003979); and to JL from National Natural Science Foundation of China (81072225, 81272951), Natural Science Foundation of Guangdong Province (10251008901000022), Specialized Research Fund for the Doctoral Program of Higher Education (20110171110068) and Science and Technology Project of Guangzhou City (11C22060035); and to LS from China Postdoctoral Science Foundation (2012M521649).

\section{CONFLICT OF INTEREST}

The authors declare no conflict of interest.

\section{REFERENCES}

Al Moustafa AE, Achkhar A, Yasmeen A (2012) EGF-receptor signaling and epithelial-mesenchymal transition in human carcinomas. Front Biosci (School Ed) 4: 671-684.

Arpin M, Chirivino D, Naba A, Zwaenepoel I (2011) Emerging role for ERM proteins in cell adhesion and migration. Cell Adhes Migr 5: 199-206.

Baumgartner M, Sillman A, Blackwood E, Srivastava JMN, Schilling JW, Wright JH, Barber DL (2006) The Nck-interacting kinase phosphorylates ERM proteins for formation of lamellipodium by growth factors. Proc Natl Acad Sci USA 103: 13391-13396.

Chai KX, Cheng J-C, Auersperg N, Leung PCK (2012) EGF-induced EMT and invasiveness in serous borderline ovarian tumor cells: a possible step in the transition to low-grade serous carcinoma cells? PLoS One 7: e34071.

Chaudhury A, Hussey GS, Ray PS, Jin G, Fox PL, Howe PH (2010) TGF- $\beta$-mediated phosphorylation of hnRNP E1 induces EMT via transcript-selective translational induction of Dab2 and ILEI. Nat Cell Biol 12: 286-293.

Chen Y, Wang D, Guo Z, Zhao J, Wu B, Deng H, Zhou T, Xiang H, Gao F, Yu X, Liao J, Ward T, Xia P, Emenari C, Ding X, Thompson W, Ma K, Zhu J, Aikhionbare F, Dou K, Cheng SY, Yao X (2011) Rho kinase phosphorylation promotes ezrin-mediated metastasis in hepatocellular carcinoma. Cancer Res 71: 1721-1729.
Chiang Y, Chou C, Hsu K, Huang Y, Shen M (2008) EGF upregulates $\mathrm{Na}^{+} / \mathrm{H}^{+}$exchanger NHE1 by post-translational regulation that is important for cervical cancer cell invasiveness. J Cell Physiol 214: 810-819.

Chuan YC, Iglesias-Gato D, Fernandez-Perez L, Cedazo-Minguez A, Pang ST, Norstedt G, Pousette Å, Flores-Morales A (2009) Ezrin mediates c-Myc actions in prostate cancer cell invasion. Oncogene 29: 1531-1542.

Crepaldi TGA, Comoglio PM, Louvard D, Arpin M (1997) ezrin is an effector of hepatocyte growth factor-mediated migration and morphogenesis in epithelial cells. J Cell Biol 138: 423-434.

Elliott BE, Meens JA, SenGupta SK, Louvard D, Arpin M (2005) The membrane cytoskeletal crosslinker ezrin is required for metastasis of breast carcinoma cells. Breast Cancer Res 7: R365.

Gan Y, Shi C, Inge L, Hibner M, Balducci J, Huang Y (2010) Differential roles of ERK and Akt pathways in regulation of EGFR-mediated signaling and motility in prostate cancer cells. Oncogene 29: 4947-4958.

Gautreau A, Poullet P, Louvard D, Arpin M (1999) Ezrin, a plasma membrane-microfilament linker, signals cell survival through the phosphatidylinositol 3-kinaseAkt pathway. Proc Natl Acad Sci USA 96: 7300-7305.

Gavert N, Ben-Shmuel A, Lemmon V, Brabletz T, Ben-Ze'ev A (2010) Nuclear factor- $\mathrm{\kappa B}$ signaling and ezrin are essential for L1-mediated metastasis of colon cancer cells. J Cell Sci 123: 2135-2143.

Gupta GP, Massagué J (2006) Cancer metastasis: building a framework. Cell 127: 679-695.

Hardy KM, Booth BW, Hendrix MJC, Salomon DS, Strizzi L (2010) ErbB/EGF signaling and EMT in mammary development and breast cancer. J Mammary Gland Biol Neoplasia 15: 191-199.

Huber MA, Kraut N, Beug H (2005) Molecular requirements for epithelialmesenchymal transition during tumor progression. Curr Opin Cell Biol 17: 548-558.

Huber MA AN, Baumann B, Grünert S, Sommer A, Pehamberger H, Kraut N, Beug H, Wirth T (2004) NF- $\mathrm{BB}$ is essential for epithelial-mesenchymal transition and metastasis in a model of breast cancer progression. J Clin Invest 114: 569-581.

Jemal A, Siegel R, Ward E, Hao Y, Xu J, Thun MJ (2009) Cancer statistics, 2009. CA Cancer J Clin 59: 225-249.

Kalluri R, Weinberg RA (2009) The basics of epithelial-mesenchymal transition. J Clin Invest 119: 1420-1428.

Khanna C, Wan X, Bose S, Cassaday R, Olomu O, Mendoza A, Yeung C, Gorlick R, Hewitt SM, Helman LJ (2004) The membrane-cytoskeleton linker ezrin is necessary for osteosarcoma metastasis. Nat Med 10: 182-186.

Kudo-Saito C, Shirako H, Takeuchi T, Kawakami Y (2009) Cancer metastasis is accelerated through immunosuppression during snail-induced EMT of cancer cells. Cancer Cell 15: 195-206. 
Kuo WC, Yang KT, Hsieh SL, Lai MZ (2009) Ezrin is a negative regulator of death receptor-induced apoptosis. Oncogene 29: 1374-1383.

Lim S, Ryu J, Shin JA, Shin MJ, Ahn YK, Kim JJ, Han KH (2009) Tumor necrosis factor- $\alpha$ potentiates RhoA-mediated monocyte transmigratory activity in vivo at a picomolar level. Arterioscler Thromb Vasc Biol 29: 2138-2145.

Louvet-Vallée S (2000) ERM proteins from cellular architecture to cell signaling. Biol Cell 92: 305-316.

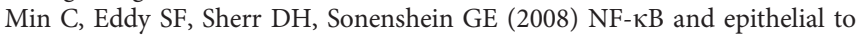
mesenchymal transition of cancer. J Cell Biochem 104: 733-744.

Polyak K, Weinberg RA (2009) Transitions between epithelial and mesenchymal states: acquisition of malignant and stem cell traits. Nat Rev Cancer 9: 265-273.

Ren L, Hong SH, Cassavaugh J, Osborne T, Chou AJ, Kim SY, Gorlick R, Hewitt SM, Khanna C (2008) The actin-cytoskeleton linker protein ezrin is regulated during osteosarcoma metastasis by PKC. Oncogene 28: 792-802.

Sánchez-Tilló E, Lázaro A, Torrent R, Cuatrecasas M, Vaquero EC, Castells A, Engel P, Postigo A (2010) ZEB1 represses E-cadherin and induces an EMT by recruiting the SWI/SNF chromatin-remodeling protein BRG1. Oncogene 29: 3490-3500.

Sano D, Myers Jeffrey N. (2007) Metastasis of squamous cell carcinoma of the oral tongue. Cancer Metast Rev 26: 645-662.

Shin SY, Rath O, Zebisch A, Choo SM, Kolch W, Cho KH (2010) Functional roles of multiple feedback loops in extracellular signal-regulated kinase and Wnt signaling pathways that regulate epithelial-mesenchymal transition. Cancer Res 70: 6715-6724.

Sizemore S, Cicek M, Sizemore N, Ng KP, Casey G (2007) Podocalyxin increases the aggressive phenotype of breast and prostate cancer cells in vitro through its interaction with ezrin. Cancer Res 67: 6183-6191.

Srivastava J, Elliott B, Louvard D, Arpin M (2005) Src-dependent Ezrin phosphorylation in adhesion-mediated signaling. Mol Biol Cell 16: 1481-1490.

Sun L, Yao Y, Liu B, Lin Z, Lin L, Yang M, Zhang W, Chen W, Pan C, Liu Q, Song E, Li J (2012) MiR-200b and miR-15b regulate chemotherapy-induced epithelial-mesenchymal transition in human tongue cancer cells by targeting BMI1. Oncogene 31: 432-445.

Thiery JP, Acloque H, Huang RYJ, Nieto MA (2009) Epithelial-mesenchymal transitions in development and disease. Cell 139: 871-890.

Thiery JP, Sleeman JP (2006) Complex networks orchestrate epithelialmesenchymal transitions. Nat Rev Mol Cell Biol 7: 131-142.

Vanacker J-M, Zheng S, Huang J, Zhou K, Zhang C, Xiang Q, Tan Z, Wang T, Fu X (2011) $17 \beta$-Estradiol enhances breast cancer cell motility and invasion via extra-nuclear activation of actin-binding protein Ezrin. PLoS One 6: e22439.

Vuoriluoto K, Haugen H, Kiviluoto S, Mpindi JP, Nevo J, Gjerdrum C, Tiron C, Lorens JB, Ivaska J (2010) Vimentin regulates EMT induction by Slug and oncogenic H-Ras and migration by governing Axl expression in breast cancer. Oncogene 30: 1436-1448.

Wellner U, Schubert J, Burk UC, Schmalhofer O, Zhu F, Sonntag A, Waldvogel B, Vannier C, Darling D, Az Hausen, Brunton VG, Morton J, Sansom O, Schüler J, Stemmler MP, Herzberger C, Hopt U, Keck T, Brabletz S, Brabletz T (2009) The EMT-activator ZEB1 promotes tumorigenicity by repressing stemness-inhibiting microRNAs. Nat Cell Biol 11: 1487-1495.

Wu Y, Deng J, Rychahou PG, Qiu S, Evers BM, Zhou BP (2009) Stabilization of Snail by NF- $\kappa B$ is required for inflammation-induced cell migration and invasion. Cancer Cell 15: 416-428.

Yip MK, Seow HF (2012) Activation of phosphatidylinositol 3-kinase/Akt signaling by EGF downregulates membranous E-cadherin and $\beta$-catenin and enhances invasion in nasopharyngeal carcinoma cells. Cancer lett 318: $162-172$.

This work is published under the standard license to publish agreement. After 12 months the work will become freely available and the license terms will switch to a Creative Commons AttributionNonCommercial-Share Alike 3.0 Unported License.

Supplementary Information accompanies this paper on British Journal of Cancer website (http://www.nature.com/bjc) 